\title{
Investigation of the Effect of Acceptance and Commitment Psychotherapy (ACT) on Quality of Life of Adult Women Suffering from Obesity
}

\author{
Gholam Abbas Jadidi*, Hamid Kazemi-Zahrani \\ ${ }^{1}$ Department of Psychology, Najafabad Branch, Islamic Azad University, Najafabad, Iran \\ ${ }^{2}$ Department of Psychology, Payame Noor University, Tehran, Iran \\ Email: "tarjomeh4u@gmail.com
}

Received 17 December 2015; accepted 26 February 2016; published 29 February 2016

Copyright (C) 2016 by authors and Scientific Research Publishing Inc.

This work is licensed under the Creative Commons Attribution International License (CC BY). http://creativecommons.org/licenses/by/4.0/

(c) (i) Open Access

\section{Abstract}

Background and Purpose: Quality of life as an important factor in health is very important. This study is looking for an appropriate and effective treatment for improving quality of life. This research aims to study the psychological effect of acceptance and commitment therapy (ACT) on quality of life of adult women suffering from obesity. Methods and Materials: This research is a kind of half-trail, with pattern of pre-test, post-test and group control. Statistical population includes all over-weight women with body mass index (BMI) range (30 - 40) who participated in family training sessions held in Shahin Shahr city. 40 patients who had the characteristics for sampling were selected and randomly placed in test and control groups (each group 20 people). Participants in each group before and after intervention quality of life questionnaire with 100 question sample World Health Organization Quality of Life (WHOQOL)-100 were evaluated. 12 sessions of acceptance and commitment therapy in group was used. The obtained data were analyzed with the use of Sciences Statistical Package for the Social (SPSS) 18 statistical software and methods of analysis of covariance. Findings: After selection of adult women having a BMI between 30 and 40 based on availability who had attended the meeting of family education, by invitation and voluntary, they were randomized into experimental and control groups. Intervention was done for experimental group. Due to the result of covariance analysis on the post-test stage, examination group showed significant improvement in variants physical health dimensions, level of independence in social and environmental relationships and spirituality $(p<0.01)$. Conclusion: According to the findings of this research based on the impact of acceptance and commitment intervention on promotion and improving in quality of life, this treatment can be used for improving the variants in women suffering from over-weight and obesity.

${ }^{*}$ Corresponding author.

How to cite this paper: Jadidi, G.A. and Kazemi-Zahrani, H. (2016) Investigation of the Effect of Acceptance and Commitment Psychotherapy (ACT) on Quality of Life of Adult Women Suffering from Obesity. Open Journal of Medical Psychology, 5, 27-34. http://dx.doi.org/10.4236/ojmp.2016.52004 


\section{Keywords}

\section{Body Mass Index, Obesity, Acceptance and Commitment Therapy Interventions, Quality of Life, Physical Health, Level of Independency, Social and Environmental Relationships, Spirituality}

\section{Introduction}

Mankind is always looking for reaching the highest level of health. One of the greatest obstacles on his way is obesity. Obesity intrigues other diseases. By far many process are detected that are related to obesity such as over eating, lack of exercise, inheritance, metabolism, environmental factors, use of drugs and mental and social process [1]. Investigations at globe level show that around two billion people around the world are overweight or obese [2]. A report stated that according to conducted studies, 17 million people above 20 in Iran are overweight and 7 million people have obesity. Around 43\% of them are men and 57\% are women [3].

One of the main components in gaining weight is the quality of life. Quality of life is what the person gets from his life position according to the culture and education system that he lives in, which is affected by the goals, expectations and standards [4]. In fact obesity is a major epidemic for health and in a good controlled situation weight loss programs result in acceptable outcome, but over the time it returns back. The effect of the quality of life on overweighting and obesity is seriously evident [5]. Quality of life as a concept, concepts and many features included in the total integrated in a quality of a person's life forms. With improvement in every area, it is expected to improve the overall quality of life [6]. Obese women's issues include various aspects of physique, psychology, interpersonal relationship, emotion, personality, spirituality, and other dimensions. In obese women, high levels of irascible character, vulnerability, passivity, insecurity, nervousness and a feeling of weakness associated with the quality and style of life [7].

Acceptance and commitment therapy is a behavioral treatment that uses mindfulness skills, acceptance and cognitive diffusion to increase psychological flexibility [8]. Psychological flexibility is to increase the ability of clients to make connection with their experience in present and to select based on what is possible for them in the moment and act in a manner that conforms the values they selected [9].

Psychological flexibility in acceptance and commitment therapy is created through 6 main processes: acceptance, cognitive diffusion, self as context, being present, defining valued directions and committed action. Each one of these process is associated with each other [10]. In the committed action therapist encourages the patient to have commitment to changes in her behavior and is focused on the changeable areas of the behavior (lucid behavior) [11]. This therapeutic approach focuses on connection to present time with desire which serves the psychological flexibility [12].

The research also aims, by using the psychotherapy process of acceptance and commitment therapy, to study the effectiveness of this method on improvement of quality of life.

Result of the research conducted by Angela L. Stottsa [13] and Feros, DL [14] showed that acceptance and commitment therapy could be effective in improving quality of life. Results of studies of Niemeier et al. [15], Karen, Michael \& Ruth [16], Tapper \& Shaw [17], Lillis [5], showed that acceptance and commitment therapy can be effective in improving the life of patients.

In the studies conducted in Iran, we didn't find a research which shows the impact of acceptance and commitment therapy on the quality of life of adult women. Therefore this research aims to study the impact of acceptance and commitment therapy on quality of life, so the hypothesis is that acceptance and commitment therapy has impact on quality of life of adult women suffering from obesity.

\section{Research Methods}

In this research experimental study methods, pre-test and post-test with group control and the non-random selection of participants was used. Statistical society included all over-weight and obese women who take part in family training sessions in Shahin Shahr, Esfahan and were invited to participate in this research. Then 40 obese women aged 25 to 40 and the BMI 30 to 40 interested in research after clinical interview based on DSM-IV criteria to make sure they do not have mental disorders and after receiving the entry criteria and the consent to participate in therapy sessions were selected purposefully. For motivating them to cooperate and taking part in the 
research the method of distribution of leaflets and introducing the study were used.

Variants of the study in pre-test stage were measured in two groups. In the next stage, these people randomly were placed in two experimental group control group. Experimental group for 12 sessions each 90 minute was under the (ACT) and the control group received no intervention. After conducting intervention sessions, variants of the study in post-test stage were measured. To implement the follow-up stage, one month later the variants were measured again.

\section{Method of Conducting the Research}

Participants of the study were adult women aged 25 to 40 and were sampled among participants in family training courses in Shahin Shahr Esfahan. Participants were selected among the volunteers who had the diagnostic criteria as sample for this research. Then were randomly tested and controlled in two groups. Dependent variable in pre-test stage was measured in groups. This evaluation includes performance of quality of life questionnaire of the world health organization (WHOQOL-100). After acceptance and commitment intervention therapy for two month in 12 sessions, each session 90 minutes, experiment were conducted in the experiment group, but control group received no intervention. After all sessions were held, all participants were again evaluated one month later.

In this study, used two groups design with pre-test and post-test. The data were analyzed using multivariate analysis of covariance and using the statistical software SPSS 18.

\section{Research Instruments}

Measuring body mass index formula: BMI or Quetelet index is a statistical evaluation to compare weight and height of a person [1]. This index was invented by Belgian scientist Adolf Quetelet between 1830 and 1850. It is very simple to calculate and in many places is used to determine to gain weight or lose weight. We can divide weight $(\mathrm{kg})$ by height $(\mathrm{m})$ and again divide the obtained number by height. In other words BMI is your weight (kg) over your height squared. However there are doubts about desirable BMI but commonly it is accepted that BMI 20 - 25 indicates normal and healthy weight. BMI 25 - 27 indicates increase in health risk, BMI above 27 shows obvious increase of risk and BMI above 30 indicates obesity and increase in health risk [18].

Quality of life questionnaire (WHOQOL-100): to assess participant's quality of life the world life quality questionnaire is used. The questionnaire was prepared by the world health organization [2] in 1995 in order to evaluate individuals' quality of life. This test is a self-report that assesses quality of life's 6 dimensions in 24 aspects. These six dimensions are: physical health dimension: pain and discomfort, energy and fatigue, sleep and rest. Psychological dimension: positive emotions, thinking and learning, self-steam appearance and body image, negative emotions. Level of independency dimension: moving and relocation, every day activities, dependence on medication or treatment, working capacity. Social relationships: individual relationships, social support, sexual activities. Environmental dimensions: physical safety and security, home, financial resources, health and social care, opportunity to gain information and learning new skills, participate in recreation activities, physical environment, and transport. Spiritual dimension: spirituality, religion, individual beliefs [2].

In this questionnaire total score of quality of life dimensions and the score of subscales are individually computable. This questionnaire is normalized by Karimlo and partners [19] in Iran. Coronbach's alpha amount in Iranian sample is $78 \%$ and concurrent validity obtained in Iran by using Pearson correlation for different dimensions indicate positive amounts. Discriminated validity in Persian version with $t$ and two independent groups and Regression analysis, the findings suggest the acceptable reliability of this scale (Table 1).

\section{Findings}

In the experiment group and people (45\%) were in group of diploma (60\%) people group of Associate's Degree, 7 people (35\%) had BA, 2 people (10\%) had MA. In control group 11 people (55\%) had diploma and (40\%) 1 had Associate's Degree, 1 person (5\%) had MA.

\subsection{The Main Hypothesis}

Acceptance and commitment therapy effect on improving the quality of life of adult women suffering from obesity in post-test and follow-up stage is evident effective. 


\begin{tabular}{|c|c|}
\hline $1^{\text {st }}$ session & $\begin{array}{l}\text { Welcome to Group, interview, measuring BMI "reforming pre-test stage” introducing the therapist "introducing } \\
\text { members' giving explanation about overweighting and obesity”, causes and effects, getting feedback from prepara- } \\
\text { tion meeting 'giving explanation. }\end{array}$ \\
\hline $2^{\text {nd }}$ session & $\begin{array}{l}\text { Talking about secrecy and principles of the group, Specifying the Therapeutic relationship, Introducing the } \\
\text { overall treatment plan, treatment purposes, determine the expectations from members in the course of treatment, } \\
\text { Openness in the group, Conclusion. }\end{array}$ \\
\hline $3^{\text {rd }}$ session & Introduction to creative hopelessness, Conclusion. \\
\hline $4^{\text {th }}$ session & $\begin{array}{l}\text { Performance evaluation “Feedback from previous session” homework Review creative hopelessness "Using related } \\
\text { metaphors, performance evaluation' homework” Conclusion. }\end{array}$ \\
\hline $5^{\text {th }}$ session & $\begin{array}{l}\text { performance evaluation, Feedback from previous session "homework Review” introducing control as an issue } \\
\text { "Using related metaphors' homework" Conclusion. }\end{array}$ \\
\hline $6^{\text {th }}$ session & $\begin{array}{l}\text { performance evaluation, Feedback from previous session, homework Review "Introducing the } \\
\text { tendency/acceptance, behavioral commitment” Using related metaphors "homework" conclusion. }\end{array}$ \\
\hline $7^{\text {th }}$ session & $\begin{array}{l}\text { The need to assess the progress, Feedback from previous session and Control of progress, expression of Feelings, } \\
\text { thoughts and experiences of new members, eliminating the ambiguity' Using related metaphors, To ensure moving } \\
\text { forward, Conclusion. }\end{array}$ \\
\hline $8^{\text {th }}$ session & $\begin{array}{l}\text { Performance evaluation “Feedback from previous session” homework Review and Behavioral commitment and } \\
\text { introducing himself as cognitive diffusion “Using related metaphors’ homework” conclusion. }\end{array}$ \\
\hline $9^{\text {th }}$ session & $\begin{array}{l}\text { Performance evaluation, Feedback from previous session, practicing homework and committed behavior } \\
\text { "Consolidation of introducing self as context and cognitive diffusion, practicing behavioral commitment, Using } \\
\text { related metaphors" homework, conclusion. }\end{array}$ \\
\hline $10^{\text {th }}$ session & $\begin{array}{l}\text { Performance evaluation, Feedback from previous session "homework Review, introducing values and obstacles } \\
\text { (values homework)" Using related metaphors "homework" conclusion. }\end{array}$ \\
\hline $11^{\text {th }}$ session & $\begin{array}{l}\text { Performance evaluation, Feedback from previous session, homework Review, replacement and introduction of } \\
\text { values and obstacles (values homework), Increasing focus on behavioral commitment, Using related metaphors } \\
\text { "homework" conclusion. }\end{array}$ \\
\hline $12^{\text {th }}$ session & $\begin{array}{l}\text { Performance evaluation, Feedback from the therapy sessions homework Review follow up treatment effects' } \\
\text { studying the willingness to change in behavior “making sure of commitment” performing post-test. }\end{array}$ \\
\hline
\end{tabular}

Based on acceptance and performance therapy [20].

As you can see in Table 2: average of quality of life and its components are mentioned.

\subsection{Results}

According to the result of the Kolmogorov-Smirnov test assumption of normal scores in pre-test and in 2 groups of experimental and control confirmed. According to the Lavigne test results assumption of equality of score variances in 2 group experimental and control in the post test stage for scale research confirmed. With regard to compliance of assumption of normality and usualness of variances covariance Analysis is used for obtaining analytical results. The increase in the average of all dimensions of the quality of life in the experimental group pre-test, post-test and follow-up is visible. While you cannot see that in the control group.

Result of Table 3 shows that among the adjusted averages and quality of life scores in terms of membership in post-test and follow-up $(\mathrm{P}=0.009)$. Therefore the research hypothesis that acceptance and commitment therapy effect on quality of life of adult women in post-test stage is confirmed. The impact on the post-test stage was $27 \%$ and in follow-up stage was $59 \%$. In the post-test, test power is equal to 0.81 and Represents the sample size is sufficient. In the follow up, test power is equal to 0.99 and Represents the sample size is sufficient.

As you can see in Table 4, after eliminating the effect of concurrent variants on the dependent variable and with calculated $\mathrm{F}$ it shows that there is a meaningful difference between Weighted Mean of physical health, psychological, level of independency, social relationships, and environmental dimensions of quality of life $(\mathrm{P}=$ 0.001). Therefore this study stating that the effect of acceptance and commitment therapy on physical health, psychological, level of independency, social relationships, and environmental dimensions of quality of life in adult women suffering from obesity in post-test stage is confirmed.

The effect in post-test stage was 29, 44, and 37, 43, 43, 47 percent. Statistical power above 0/9 shows the adequate amount of sample. Also there is a meaningful difference in mean averages scores of physical health, psychological, level of independency, social relationships, and environmental dimensions of quality of life in 
Table 2. Average and standard deviation of quality of life and its dimensions in experimental group and control group. Pre-test, post-test, and follow-up.

\begin{tabular}{|c|c|c|c|c|c|c|c|}
\hline \multirow[b]{2}{*}{ variant } & \multirow[b]{2}{*}{ Group } & \multicolumn{2}{|c|}{ Pre-test } & \multicolumn{2}{|c|}{ Post-test } & \multicolumn{2}{|c|}{ Follow-up } \\
\hline & & Average & $\begin{array}{l}\text { Standard } \\
\text { deviation }\end{array}$ & Average & $\begin{array}{l}\text { Standard } \\
\text { deviation }\end{array}$ & Average & $\begin{array}{l}\text { Standard } \\
\text { deviation }\end{array}$ \\
\hline \multirow{2}{*}{ Quality of life } & Control group & 14.10 & 2.86 & 13.55 & 2.52 & 13.34 & 2.41 \\
\hline & Experiment group & 13.98 & 2.75 & 16.05 & 1.87 & 16.62 & 1.75 \\
\hline \multirow{2}{*}{ Physical health } & Control group & 13.33 & 2.89 & 13.17 & 2.59 & 13.29 & 2.46 \\
\hline & Experiment group & 13.18 & 2.89 & 15.29 & 2.01 & 15.82 & 2.10 \\
\hline \multirow[t]{2}{*}{ Psychological } & Control group & 13.95 & 1.96 & 13.29 & 1.72 & 13.34 & 1.61 \\
\hline & Experiment group & 12.61 & 2.38 & 15.62 & 2.88 & 15.50 & 1.41 \\
\hline \multirow{2}{*}{$\begin{array}{c}\text { Level of } \\
\text { independence }\end{array}$} & Control group & 14.99 & 3.13 & 14.58 & 2.81 & 14.31 & 2.74 \\
\hline & Experiment group & 15.03 & 2.48 & 16.43 & 2 & 16.54 & 2.02 \\
\hline \multirow{2}{*}{ Social relationships } & Control group & 13.50 & 2.04 & 13.37 & 1.99 & 13.35 & 2.07 \\
\hline & Experiment group & 13.51 & 1.99 & 14.92 & 1.58 & 14.89 & 1.74 \\
\hline \multirow{2}{*}{ Environment } & Control group & 13.07 & 2.21 & 12.82 & 2.12 & 12.92 & 1.79 \\
\hline & Experiment group & 13.21 & 2.11 & 14.41 & 1.65 & 14.67 & 1.63 \\
\hline \multirow{2}{*}{$\begin{array}{l}\text { Spiritual/religion/ } \\
\text { personal beliefs }\end{array}$} & Control group & 15.24 & 2.25 & 15.04 & 3 & 14.59 & 2.58 \\
\hline & Experiment group & 14.50 & 3.36 & 16.25 & 2.31 & 17.10 & 1.83 \\
\hline
\end{tabular}

Table 3. Results of covariance analysis quality of life in post-test and follow up.

\begin{tabular}{cccccccc}
\hline Source change & Variant & $\begin{array}{c}\text { Total } \\
\text { Squares }\end{array}$ & $\begin{array}{c}\text { Degree of } \\
\text { freedom }\end{array}$ & $\begin{array}{c}\text { Mean } \\
\text { square }\end{array}$ & F & Significance & Squares \\
power & Test & 0.81 & 0.009 & 0.27 \\
$\begin{array}{c}\text { Post-test group } \\
\text { membership }\end{array}$ & Quality of life & 19.34 & 1 & 19.34 & 8.34 & 0.001 & 0.59 \\
$\begin{array}{c}\text { Follow up group } \\
\text { membership }\end{array}$ & Quality of life & 74.96 & 1 & 74.96 & 43.79 & 0.99 \\
\hline
\end{tabular}

Table 4. Result of analysis of covariance on quality of life dimensions in post-test and follow-up stages.

\begin{tabular}{|c|c|c|c|c|c|c|c|c|}
\hline Source change & Variant & $\begin{array}{c}\text { Total } \\
\text { Squares }\end{array}$ & $\begin{array}{l}\text { Degree of } \\
\text { freedom }\end{array}$ & $\begin{array}{l}\text { Mean } \\
\text { square }\end{array}$ & $\mathrm{F}$ & Significance & $\begin{array}{l}\text { Share } \\
\text { square }\end{array}$ & $\begin{array}{c}\text { Test } \\
\text { powers }\end{array}$ \\
\hline \multirow{6}{*}{$\begin{array}{c}\text { Post-test } \\
\text { membership }\end{array}$} & Physical health & 40.26 & 1 & 40.26 & 23.52 & 0.001 & 0.47 & 0.99 \\
\hline & Psychological & 82.49 & 1 & 82.49 & 2.74 & 0.001 & 0.43 & 0.99 \\
\hline & Level of independence & 23.62 & 1 & 23.62 & 2.39 & 0.001 & 0.43 & 0.99 \\
\hline & Social relationships & $56 / 22$ & 1 & 22.56 & 15.89 & 0.001 & 0.37 & 0.97 \\
\hline & Environment & 15.87 & 1 & 15.87 & 21.60 & 0.002 & 0.44 & 0.99 \\
\hline & $\begin{array}{l}\text { Spiritual/religion/ } \\
\text { personal beliefs }\end{array}$ & 36.08 & 1 & 36.08 & 11.22 & 0.002 & 0.29 & 0.90 \\
\hline \multirow{6}{*}{$\begin{array}{l}\text { Follow-up } \\
\text { group } \\
\text { membership }\end{array}$} & Physical health & 31.76 & 1 & 31.76 & 11.42 & 0.002 & 0.30 & 0.90 \\
\hline & Psychological & 48.74 & 1 & 48.74 & 40.81 & 0.001 & 0.60 & 0.99 \\
\hline & Level of independence & 37.77 & 1 & 37.77 & 18.32 & 0.001 & 0.40 & 0.98 \\
\hline & Social relationships & 13.19 & 1 & 13.19 & 8.42 & 0.007 & 0.24 & 0.80 \\
\hline & Environment & 26.89 & 1 & 26.89 & 48.18 & 0.001 & 0.64 & 0.99 \\
\hline & $\begin{array}{l}\text { Spiritual/religion/ } \\
\text { personal beliefs }\end{array}$ & 67.65 & 1 & 67.65 & 17.18 & 0.001 & 0.39 & 0.98 \\
\hline
\end{tabular}


terms of group membership in follow-up stage. Therefore research hypnosis stating that the effect of acceptance and commitment therapy on physical health, psychological, level of independency, social relationships, and environmental dimensions of quality of life in adult women suffering from obesity in follow-up stage is confirmed. Impact on the follow-up stage was 30, 60, and 40, 24, 64, 39 percent.

\section{Discussion}

Result of current study in the effect of acceptance and commitment therapy on quality of life of adult women suffering from obesity is corresponding with the result of previous studies. Quality of life improved in follow-up stage. In line with Hayes [21] saying, that one of the fundamental purposes of acceptance and commitment approach is improving the quality of life, according to the researcher's studies and in all researches that aimed to study the effect of ACT, improving the quality of life was considered to be prologue for BMI reduction. Which means it is possible that improving quality of life leads to modifying food style and physical mobility and that in turn result promotion in quality of life. As it is obvious in Niemeier and associates [15] studies, when participants reached the acceptance stage, evaluation and analysis of quality of life consciously was begun. This issue was evident after the fourth session. It seems that before this stage, there was resistance to the protection of current life style. Therefore rush in changes in patient may lead to treatment failure. Quality of life in obese people because of problems in feelings and thoughts in underlying layers of behavior is not at desirable level. Probably improving quality of life leads to acceptance of feelings and thoughts and then change in behavior, life style and weight loss.

\section{Conclusions}

About quality of life components we can say that when we talk about quality of life in conducted studies it includes its six dimensions. Results of this study in terms of effectiveness on improving the physical dimension are in line with other investigations in this field [5] [14] [15] [22] [23]. Acceptance and commitment therapy by creating values for patients causes motivation of health in physical dimension. This issue is present in both Angiola and Bwen studies [22]. Some psychological factors such as fear of judgment about himself and others, intolerance in commitment and adherence are emotional factors in obesity that result in depression, decline in physical activity, failure in commitment for their health and weight regain. Reduction in these emotional factors that begin from cognitive diffusion stage led to fat growth in lost performances of patients.

After learning the separation of behaviors and, though, and feeling that include emotions commenced, with the recognition of emotional factors, patient willingness to physical exercises as a behavior was increased. In line with Fletcher and Hayes [24], when commitment acted after the values stage created, adherence to physical changes was strengthened. Results of this study in terms of the impact on improving the psychological dimension of quality of life are in line with other studies in this field [5] [14] [15] [22] [23]. Creating psychological flexibility which is one of the treatment stages in this study and Feros [14], leads to leaving aside the wrong habits and results in improving quality of life in physical health dimension. Results of this study in terms of impact on improving the level of independency of quality of life are in line with other studies in this field [5] [14] [15] [22] [23].

Obese people because of emotional characteristics and the fear of malformation of body have difficulties in making decisions. Extending dependence to others approval provokes this problem and increases the fear of failure. In this case patients from the tendency to acceptance stage realize their dependency and reconsider their dependent behaviors. This group enhances their tendency to new experiences.

Primary action in improving quality of life of the person is not being dependent to others shown in the research. Results of this study in terms of impact on improving the social relationships dimensions in quality of life, are in line with other studies in this field [5] [14] [15] [22] [23]. With acceptance of thoughts and negative feelings, and increasing the psychological flexibility, improvement in distress, mood and quality of life was observed. Fear of judgment about himself and others and, intolerance in commitment and adherence to health care which are emotional factors, are effective in obesity. A social relationship is a fundamental principle in quality of life. Because persons are influenced by the people who interact with and have influence over them also. In experiment group some patients were not willing to co-operate and take part in activities and were suffering from a kind of isolation, but after inaction, impulsivity or avoidant persistence to commitment action changes in social interactions was observed. Result of this study in terms of impact on environmental dimension of quality 
of life was in line with other investigations in this field [5] [14] [15] [22] [23]. Overeating is in response to negative emotions in life such as, tiredness, stress, dissatisfaction of living environment and external factors of eating related to tension in response to food stimuli, such as taste, lighting testing a served food. This issue in the present study in terms of dissatisfaction of life, physical environment such as house, district and the people person which is optional or compulsorily is in contact is important. Performing the quality of life questionnaire in post-test stage showed that these people more trusted the environment. Considering this issue, the persons' environmental satisfaction especially in mindfulness stage which comes after the acceptance was improved. Results of this study in terms of improving spirituality dimension of quality of life are in line with other investigations in this field [5] [14] [15] [22] [23].

As it came in the results of quality of life dimension questionnaire, after finishing the course, relying on God was the mean spiritual source which was enhanced. One factor of acceptance and commitment therapy is faith and belief. In Iranian and Islamic culture that faith in God and human nature in terms of spirituality is very important, this approach is very obvious. Acceptance and commitment therapy helps people to accept the situation which is against their beliefs. Faith and spirituality help the mental health of the participants, because they get help from what they profoundly believe to reach tranquility.

\section{Limitations}

This study had some limitations:

1) It was difficult to select participants with common characteristics at the same time they did not use the other methods of weight loss.

2) BMI is a multi-factorial variable; therefore, it is necessary measurement tools such as the appetite, tendency to physical activity, stress measurement, measuring measurement emotional mental energy.

3) Evaluation of these factors can help researchers explain better hypotheses, although repeatedly questioned and evaluated in the process of acceptance and commitment therapy.

\section{Acknowledgements}

Thanks to Professors and dear colleagues in Education Department and also participants who helped the researcher in conducting the research.

\section{References}

[1] Kirby Jane, R.D. (2003) Dieting for Dummies. 2nd Edition, Wiley Publishing, Hoboken.

[2] World Health Organization (2012) World Health Statistics.

[3] Azizi, F. (2013) Head of the Association of Preventing and Curing Obesity of Iran, Jamejam, Iran. News Code: 1282567675114745936

[4] Scott, N.W., Fayers, P.M., Aaronson, N.K., et al. (2008) EORTC Reference Manual. EORTC Quality of Life Group, Brussels.

[5] Lillis, J. (2008) Acceptance and Commitment Therapy for the Treatment of Obesity-Related Stigma and Sustained Weight Loss. Unpublished Doctoral Dissertation, University of Nevada, Reno.

[6] Felce, D. and Perry, J. (1995) Quality of Life: Its Definition and Measurement. Research in Developmental Disabilities, 16, 51-74. http://dx.doi.org/10.1016/0891-4222(94)00028-8

[7] Ryden, A., Sullivan, M., Torgerson, J.S., Karlsson, J., Lindroos, A.K. and Taft, C. (2003) Severe Obesity and Personality: A Comparative Controlled Study of Personality Traits. International Journal of Obesity, 27, 1534-1540. http://dx.doi.org/10.1038/sj.ijo.0802460

[8] Herbert, J.D. and Forman, E.M. (2011) Acceptance and Mindfulness in Cognitive Behavior Therapy. Wiley. Hoboken. http://dx.doi.org/10.1002/9781118001851

[9] Hayes, S.C. and Strosahl, K.D. (2010) A Practical Guide to Acceptance and Commitment Therapy. Springer Science and Business Media Inc., New York.

[10] Hayes, S.C., Masuda, A., Bissett, R., Luoma, J. and Guerrero, L.F. (2004) DBT, FAP, and ACT: How Empirically Oriented Are the New Behavior Therapy Technologies? Behavior Therapy, 35, 35-54.

[11] Hayes, S.C., Levin, M., Plumb, J., Boulanger, J. and Pistorello, J. (2013) Acceptance and Commitment Therapy and Contextual Behavioral Science: Examining the Progress of a Distinctive Model of Behavioral and Cognitive Therapy. 
Behavior Therapy, 44, 180-198. http://dx.doi.org/10.1016/j.beth.2009.08.002

[12] Hayes, S.C., Luoma, J.B., Bond, F.W., Masuda, A. and Lillis, J. (2006) Acceptance and Commitment Therapy: Model, Processes and Outcomes. Behaviour Research and Therapy, 44, 1-25. http://dx.doi.org/10.1016/j.brat.2005.06.006

[13] Stotts, A.T.L., Green, C., Masuda, A., Grabowski, J., Wilson, K., Northrup, T.F., Moeller, F.G. and Schmitz, J.M. (2012) A Stage I Pilot Study of Acceptance and Commitment Therapy for Methadone Detoxification. Drug and Alcohol Dependence, 125, 215-222. http://dx.doi.org/10.1016/j.drugalcdep.2012.02.015

[14] Feros, D.L., Lane, L., Ciarrochi, J. and Blackledge, J.T. (2013) Acceptance and Commitment Therapy (ACT) for Improving the Lives of Cancer Patients: A Preliminary Study. Psycho-Oncology, 22, 459-464.

[15] Niemeier, H.M., Leahey, T., Reed, K.P., Brown, R.A. and Wing, R.R. (2012) An Acceptance-Based Behavioral Intervention for Weight Loss: A Pilot Study. Behavior Therapy, 43, 427-435. http://dx.doi.org/10.1016/j.beth.2011.10.005

[16] Caldwell, K., Baime, M. and Wolever, R.Q. (2012) Mindfulness Based Approaches to Obesity and Weight Loss Maintenance. Journal of Mental Health Counseling, 34, 269-282. http://dx.doi.org/10.17744/mehc.34.3.t016616717774643

[17] Tapper, K., Shaw, C. and Moore, L. (2007) Development and Piloting of an Acceptance Based Intervention for Overweight and Obese Women. ReF05/1/071 Final Report.

[18] Sadock, B.J. and Sadock, V.A. (2010) Kaplan and Sadock’s Pocket Handbook of Clinical Psychiatry, 5th Edition. Lippincott Williams and Wilkins, Philadelphia.

[19] Karimlo, M., Salehi, M., Zaeri, F., Cholabi, O.M., Hatami, A. and Khatata, M.M. (2010) Development of Persian Version of the World Health Organization's Quality of Life-100 Questionnaire. Rehabilitation Journal of Iran, 11, 73.

[20] Hayes, S.C., Strosahl, K. and Wilson, K.G. (1999) Acceptance and Commitment Therapy: An Experiential Approach to Behavior Change. Guilford Press, New York.

[21] Hayes, S.C. (2008) Climbing Our Hills: A Beginning Conversation on the Comparison of Acceptance and Commitment Therapy and Traditional Cognitive Behavioral Therapy. Clinical Psychology: Science and Practice, 15, $286-295$. http://dx.doi.org/10.1111/j.1468-2850.2008.00139.x

[22] Angiola, J.E. and Bwen, A.M. (2013) Quality of Life in Advanced Cancer: An Acceptance and Commitment Therapy View. The Counseling Psychologist, 41, 313-335. http://dx.doi.org/10.1177/0011000012461955

[23] Forman, E.M., Butryn, M.L., Hoffman, K.L. and Herbert, J.D. (2009) An Open Trial of an Acceptance-Based Behavioral Intervention for Weight Loss. Cognitive and Behavioral Practice, 16, 223-235. http://dx.doi.org/10.1016/j.cbpra.2008.09.005

[24] Fletcher, L. and Hayes, S.C. (2011) A Mindfulness and Acceptance-Based Intervention for Increasing Physical Activity and Reducing Obesity. UMI Number: 3490761. ProQuest LLC, Ann Arbor. 